\title{
Systematic Investigation of Gettering Effects on 4th Row Element Impurities in Si by Dopant Atoms
}

\author{
Koji Sueoka, Ken Kamimura, and Seiji Shiba \\ Department of System Engineering, Okayama Prefectural University, 111 Kuboki, Soja, Okayama 719-1197, Japan \\ Correspondence should be addressed to Koji Sueoka, sueoka@cse.oka-pu.ac.jp
}

Received 2 September 2009; Accepted 13 November 2009

Recommended by Richard Hennig

\begin{abstract}
The gettering of 4th row element impurities ( $\mathrm{K}, \mathrm{Ca}$, 3d transition metals, and $\mathrm{Zn}$ ) in Si crystals by dopant atoms was systematically investigated by first-principles calculation through evaluation of the diffusion barrier and the binding energy. The dopant atoms considered include p-type dopants (B), n-type dopants ( $\mathrm{P}, \mathrm{As}, \mathrm{Sb})$, or light elements (C, O). It was found that (1) the diffusion barrier of impurity atoms decreases with an increase in their atomic number up to $\mathrm{Ni}$, (2) $\mathrm{B}$ atom becomes an efficient gettering center for metals except for $\mathrm{Ni},(3)$ most of the metals except for Fe and Co cannot be gettered by n-type dopants, and (4) C and $\mathrm{O}$ atoms alone do not become efficient gettering centers for the metals used in actual LSI processes. The vacancy $V_{c}$ and n-type dopant complexes $\left(\mathrm{P} V_{c}, \mathrm{As} V_{c}, \mathrm{Sb} V_{c}\right)$ can be efficient gettering centers for $\mathrm{Cu}$ in $\mathrm{n} / \mathrm{n}+$ epitaxial wafers.
\end{abstract}

Copyright (C) 2009 Koji Sueoka et al. This is an open access article distributed under the Creative Commons Attribution License, which permits unrestricted use, distribution, and reproduction in any medium, provided the original work is properly cited.

\section{Introduction}

There is an increasing demand on "impurity gettering" technology for removing metal impurities from the LSI active region. Various techniques are reported as impurity gettering $[1,2]$. For example, a dopant atom forms a stable complex by the interaction with the metal atom under consideration. In this case, the dopant atom interacting with the metal is called "gettering center". Among the 4th element impurities, there are many reports on the gettering of the $\mathrm{Fe}$ and $\mathrm{Ni}$ incorporated to $\mathrm{Si}$ wafer mainly from the plumbing for heat-treatments $[1,2]$. Furthermore, gettering of $\mathrm{Cu}$, which is used commonly as wiring, attracts attentions in the recent LSI fabrication [3]. However, there are limited reports on $\mathrm{Ti}, \mathrm{V}, \mathrm{Cr}, \mathrm{Mn}$ and $\mathrm{Co}$ atoms that are newly in use for higher LSI performance.

First-principles calculation is the effective tool to simulate the gettering of the metals in Si crystals [3, 4]. To design the efficient gettering centers for new metals, the systematic investigations by first-principles calculation will be valuable. In this study, therefore, the gettering of 4 th element impurities ( $\mathrm{K}, \mathrm{Ca}, 3 \mathrm{~d}$ transition metals, and $\mathrm{Zn})$ in Si crystals is systematically investigated by the first-principles calculation through evaluation of the diffusion barrier and the binding energy with p-type dopants (B), n-type dopants
$(\mathrm{P}, \mathrm{As}, \mathrm{Sb})$ or light elements $(\mathrm{C}, \mathrm{O})$. Efficient gettering centers for $\mathrm{Cu}$ in $\mathrm{n} / \mathrm{n}+$ epitaxial wafers are also investigated.

\section{Calculation Methods}

The calculation method is the first-principles calculation, in which the ground state of the system is found by solving the Kohn-Sham equation that is a rule equation of the electronic system for a given atomic configuration. The program package used in this study is CASTEP [5]. Wave function is expanded by plane-waves, and ultrasoft pseudopotential [6] is used to reduce a number of plane waves. The cutoff energy for the plane-wave expansion is $310 \mathrm{eV}$. The generalized gradient approximation (GGA) is used for the exchangecorrelation term, and functional form is of PBE type [7]. The $\Gamma$ and $L$ points are used for the $k$ sampling [8].

In the calculations, a Si 64-atoms supercell, that is, $2 \times 2$ $\times 2$ supercell constructed by conventional cell, is used. The lattice parameter of Si crystal is fixed as the experimental value of $5.431 \AA$. The $\mathrm{Si}$ atom at the center of the supercell is substituted with a dopant $(\mathrm{B}, \mathrm{P}, \mathrm{As}, \mathrm{Sb})$ or $\mathrm{C}$ atom. An O atom is located at the center of Si-Si bond. A metal atom is placed at the nearest interstitial positions to the dopant. The total energy of the supercell including various complexes is calculated with the geometrical optimization. 


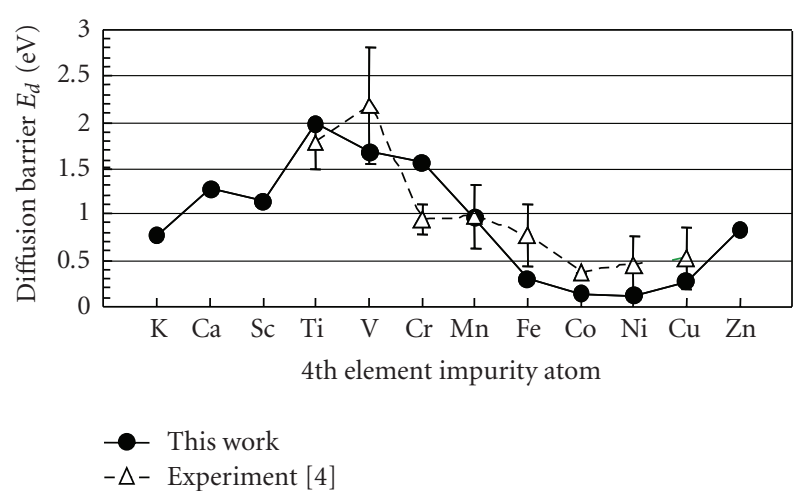

Figure 1: Calculated diffusion barrier $E_{d}$ of 4 th element impurity atoms in Si crystal.

\section{Results and Discussion}

The most stable position of $\mathrm{K}, \mathrm{Ca}, \mathrm{Sc}, \mathrm{Ti}, \mathrm{V}, \mathrm{Cr}, \mathrm{Mn}, \mathrm{Fe}$, $\mathrm{Cu}$, and $\mathrm{Zn}$ atoms is determined as interstitial $\mathrm{T}$ site from the calculated total energies. On the other hand, the most stable position of $\mathrm{Co}$ and $\mathrm{Ni}$ atoms is $\mathrm{H}$ site. Here, we assume that the metal atom diffuses as $\mathrm{T} \rightarrow \mathrm{H} \rightarrow \mathrm{T}$ sites. The diffusion barrier $E_{d}$ can be estimated by

$$
E_{d}=\mid E_{t o t}(\mathrm{H} \text {-site })-E_{t o t}(\mathrm{~T} \text {-site }) \mid .
$$

The calculated result of $E_{d}$ is shown in Figure 1. It is found that the diffusion barrier of impurity atoms decreases with an increase in their atomic number up to Ni. The obtained $E_{d}$ from $\mathrm{Ti}$ to $\mathrm{Cu}$ agrees with the experiments summarized in [4] quantitatively.

The binding energy $E_{b}$ of $\mathrm{B}$ atom to the impurity atoms is calculated by

$$
\begin{aligned}
E_{b}= & \left\{E_{\text {tot }}\left(\operatorname{Si}_{63} \mathrm{X}\right)+E_{t o t}\left(\operatorname{Si}_{64} \mathrm{M}\right)\right\} \\
& -\left\{E_{\text {tot }}\left(\mathrm{Si}_{63} \mathrm{XM}\right)+E_{\text {tot }}\left(\mathrm{Si}_{64}\right)\right\} .
\end{aligned}
$$

In this equation, $\mathrm{M}$ indicates impurity atom and $\mathrm{X}$ gettering center. Here, $\mathrm{X}=\mathrm{B}$. The sign $E_{b}>0$ means that the complex is stable. The calculated result of $E_{b}$ of $\mathrm{B}$ to $\mathrm{Fe}, \mathrm{Co}, \mathrm{Ni}$, or $\mathrm{Cu}$ atoms is summarized in Table 1 . The values of $E_{b}$ are in agreement with other calculations and experimental results quantitatively. It is well known that $\mathrm{Fe}$ and $\mathrm{Cu}$ atoms are efficiently gettered by $\mathrm{B}[1,9]$, while $\mathrm{Ni}$ is not [1]. That the calculated $E_{b}$ for $\mathrm{Ni}$ is smaller than $E_{b}$ for $\mathrm{Fe}$ and $\mathrm{Cu}$ agrees with the experimental result qualitatively.

The calculated result of $E_{b}$ of $B$ to 4 th element impurity atoms is shown in Figure 2. The $E_{b}$ of B to all the impurity atoms listed possesses a positive value, which indicates the formation of stable complexes. If we use the $E_{b}$ for $\mathrm{Fe}$ as the critical energy for efficient gettering, the calculated results in Figure 2 suggest that the 4 th element impurities except for $\mathrm{Ni}$ can be gettered by B atom. In Si crystals, a substitutional B atom is negatively charged and most interstitial metal atoms are positively charged except for $\mathrm{Ni}$. Since the $\mathrm{Ni}$ atom exists in electronically neutral state in Si crystal [1], $E_{b}$ of $\mathrm{B}$ to $\mathrm{Ni}$ should be smaller than $E_{b}$ for the other metals.
TABle 1: Binding energy $E_{b}$ of $\mathrm{B}$ to $\mathrm{Fe}, \mathrm{Co}, \mathrm{Ni}$, and $\mathrm{Cu}$ atoms.

\begin{tabular}{lcc}
\hline & & $E_{b}(\mathrm{eV})$ \\
\hline Fe-B & This work & 0.48 \\
& & 0.64 (Cal. [4]), 0.47-0.73 (Exp. [9, 10]) \\
\hline \multirow{2}{*}{ Co-B } & \multirow{2}{*}{ This work } & 0.64 \\
& & 0.65 (Cal. [4]), 0.61 (Exp. [11]) \\
\hline \multirow{2}{*}{ Ni-B } & \multirow{2}{*}{ This work } & 0.36 \\
& & 0.44 (Cal. [4]), 0.52 (Exp. [12]) \\
\hline \multirow{2}{*}{ Cu-B } & \multirow{2}{*}{ This work } & 0.61 \\
& & 0.57 (Cal. [4]), 0.43 (Exp. [9, 10]) \\
\hline
\end{tabular}

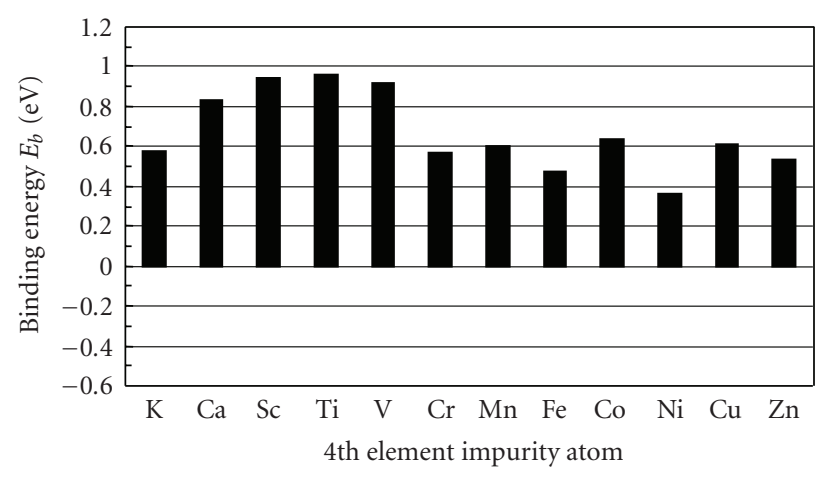

- B

FIgure 2: Calculated binding energy $E_{b}$ of $\mathrm{B}$ to 4 th element impurity atoms.

The calculated result of $E_{b}$ of n-type dopants ( $\mathrm{P}, \mathrm{As}$, or $\mathrm{Sb})$ to impurity atoms is shown in Figure 3. It is found that $E_{b}$ of $\mathrm{P}$ to $\mathrm{Fe}$ (or $\mathrm{Co}$ ) atom, and $E_{b}$ of As (or Sb) to Co atom are as high as $E_{b}$ of $\mathrm{B}$ to $\mathrm{Fe}$ atom. As a result, it can be said that (1) $\mathrm{P}$ atom can be an efficient gettering center for Fe and Co atoms, and (2) As and Sb atoms can be efficient gettering centers only for Co atom.

The calculated result of $E_{b}$ of $\mathrm{C}$ (or $\mathrm{O}$ ) to impurity atoms shows that (1) $\mathrm{C}$ atom does not become an efficient gettering center for any 4th element impurities, and (2) $\mathrm{O}$ atom has negative or small positive binding energies with impurity atoms except for $\mathrm{K}$ and $\mathrm{Ca}$ atoms. Thus it is concluded that $\mathrm{C}$ and $\mathrm{O}$ atoms alone do not become efficient gettering centers for the metals used in actual LSI processes.

In order to find an efficient gettering center for $\mathrm{Cu}$ in $\mathrm{n} / \mathrm{n}+$ epitaxial wafers, we have considered the complexes of vacancy $V_{c}$ and n-type dopant $\left(\mathrm{P} V_{c}, \mathrm{As} V_{c}, \mathrm{Sb} V_{c}\right)$. In the calculation, first, we have evaluated the binding energy of $V_{c}+\mathrm{Cu}^{\mathrm{i}} \rightarrow \mathrm{Cu}_{s}$. Here, $\mathrm{Cu}^{\mathrm{i}}$ and $\mathrm{Cu}_{\mathrm{s}}$ indicate the interstitial and the substitutional $\mathrm{Cu}$ atom, respectively. Then, the binding energy of $V_{c}+\mathrm{Cu}^{\mathrm{i}} \rightarrow \mathrm{Cu}_{\mathrm{s}}$ is taken as the reference energy for the binding energy $E_{b}$ of $\mathrm{P} V_{c}$, As $V_{c}$, $\mathrm{Sb}_{c}$ complexes to $\mathrm{Cu}$ atom. It was found in Table 2 that these complexes can be efficient gettering centers for $\mathrm{Cu}$ with forming the complexes of $\mathrm{PCu}_{\mathrm{s}}, \mathrm{AsCu}_{\mathrm{s}}$, and $\mathrm{SbCu}_{\mathrm{s}}$. This result suggests a new $\mathrm{Cu}$ gettering technique in $\mathrm{n} / \mathrm{n}+$ epitaxial wafers with using gettering centers of $\mathrm{P} V_{c}, \mathrm{As} V_{c}$, and $\mathrm{Sb} V_{c}$ complexes as the gettering center. 


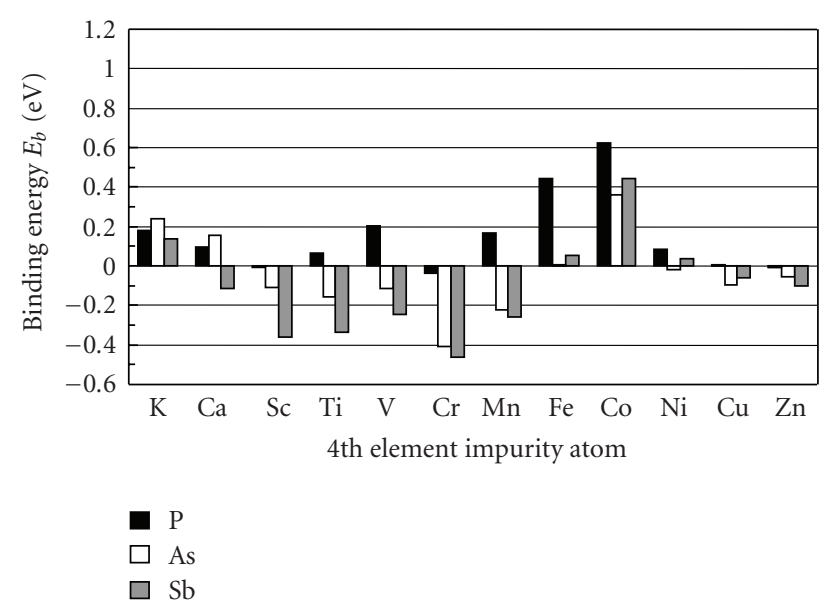

Figure 3: Calculated binding energy $E_{b}$ of $n$-type dopants to 4 th element impurity atoms.

Table 2: Calculated binding energy $E_{b}$ of $\mathrm{P} V_{c}, \mathrm{As} V_{c}, \mathrm{Sb} V_{c}$ to $\mathrm{Cu}$.

\begin{tabular}{lc}
\hline Formed Complex & $E_{b}(\mathrm{eV})$ \\
\hline $\mathrm{PCu}_{\mathrm{s}}$ & 1.34 \\
$\mathrm{AsCu}_{\mathrm{s}}$ & 1.25 \\
$\mathrm{SbCu}_{\mathrm{s}}$ & 1.09 \\
\hline
\end{tabular}

\section{Summary}

We have systematically investigated the gettering of 4 th element impurities $(\mathrm{K}, \mathrm{Ca}, 3 \mathrm{~d}$ transition metals, and $\mathrm{Zn})$ in Si crystals by first-principles calculation through evaluation of the diffusion barrier and the binding energy with p-type dopants (B), n-type dopants (P, As, Sb), or light elements (C, $\mathrm{O})$. It was found that (1) the diffusion barrier of impurity atoms decreases with an increase in their atomic number up to $\mathrm{Ni},(2) \mathrm{B}$ atom becomes an efficient gettering center for metals except for $\mathrm{Ni}$, (3) the most of the metals except for $\mathrm{Fe}$ and Co cannot be gettered by n-type dopants, and (4) C and $\mathrm{O}$ atoms alone do not become efficient gettering centers for the metals used in actual LSI processes. The vacancy $V_{c}$ and n-type dopant complexes $\left(\mathrm{P} V_{c}, \mathrm{As} V_{c}, \mathrm{Sb} V_{c}\right)$ can be efficient gettering centers for $\mathrm{Cu}$ in $\mathrm{n} / \mathrm{n}+$ epitaxial wafers.

\section{References}

[1] R. Hoelzl, M. Blietz, L. Fabry, and R. Schmolke, "Gettering efficiencies and their dependence on material parameters," in Semiconductor Silicon, pp. 608-625, The Electrochem. Soc., Pennington, NJ, USA, 2002.

[2] K. Sueoka, "Modeling of internal gettering of nickel and copper by oxide precipitates in czochralski-Si wafers," Journal of the Electrochemical Society, vol. 152, no. 10, pp. G731-G735, 2005.

[3] T. Michikita, K. Shirai, and H. Katayama-Yoshida, "Materials design for $\mathrm{Cu}$ gettering by electronic dopants in silicon," Japanese Journal of Applied Physics, vol. 44, no. 11, pp. 79047906, 2005.
[4] K. Matsukawa, "Materials design for the gettering of diffusive 3d transition elements in silicon," Ph.D. thesis, Osaka University, 2006.

[5] "The CASTEP code," Accelrys Software Inc., http://accelrys .com/products/materials-studio/modules/CASTEP.html.

[6] D. Vanderbilt, "Soft self-consistent pseudopotentials in a generalized eigenvalue formalism," Physical Review B, vol. 41, no. 11, pp. 7892-7895, 1990.

[7] J. P. Perdew, K. Burke, and M. Ernzerhof, "Generalized gradient approximation made simple," Physical Review Letters, vol. 77, no. 18, pp. 3865-3868, 1996.

[8] G. Makov, R. Shah, and M. C. Payne, "Periodic boundary conditions in ab initio calculations. II. Brillouin-zone sampling for aperiodic systems," Physical Review B, vol. 53, no. 23, pp. 15513-15517, 1996.

[9] H. Hieslmair, A. A. Istratov, C. Flink, S. A. McHugo, and E. R. Weber, "Experiments and computer simulations of iron profiles in $\mathrm{p} / \mathrm{p}+$ silicon: segregation and the position of the iron donor level," Physica B, vol. 273-274, pp. 441-444, 1999.

[10] H. Feichtinger, "Electrical and cinetic properties of thermally activated iron in silicon," Acta Physica Austriaca, vol. 51, pp. 161-189, 1979.

[11] H. Lemke and K. Irmscher, "Proof of interstitial cobalt defects in silicon float zone crystals doped during crystal growth," ECS Transactions, vol. 3, no. 4, pp. 299-310, 2006.

[12] A. A. Istratov, P. Zhang, R. J. McDonald, et al., "Nickel solubility in intrinsic and doped silicon," Journal of Applied Physics, vol. 97, no. 2, Article ID 023505, 6 pages, 2005. 

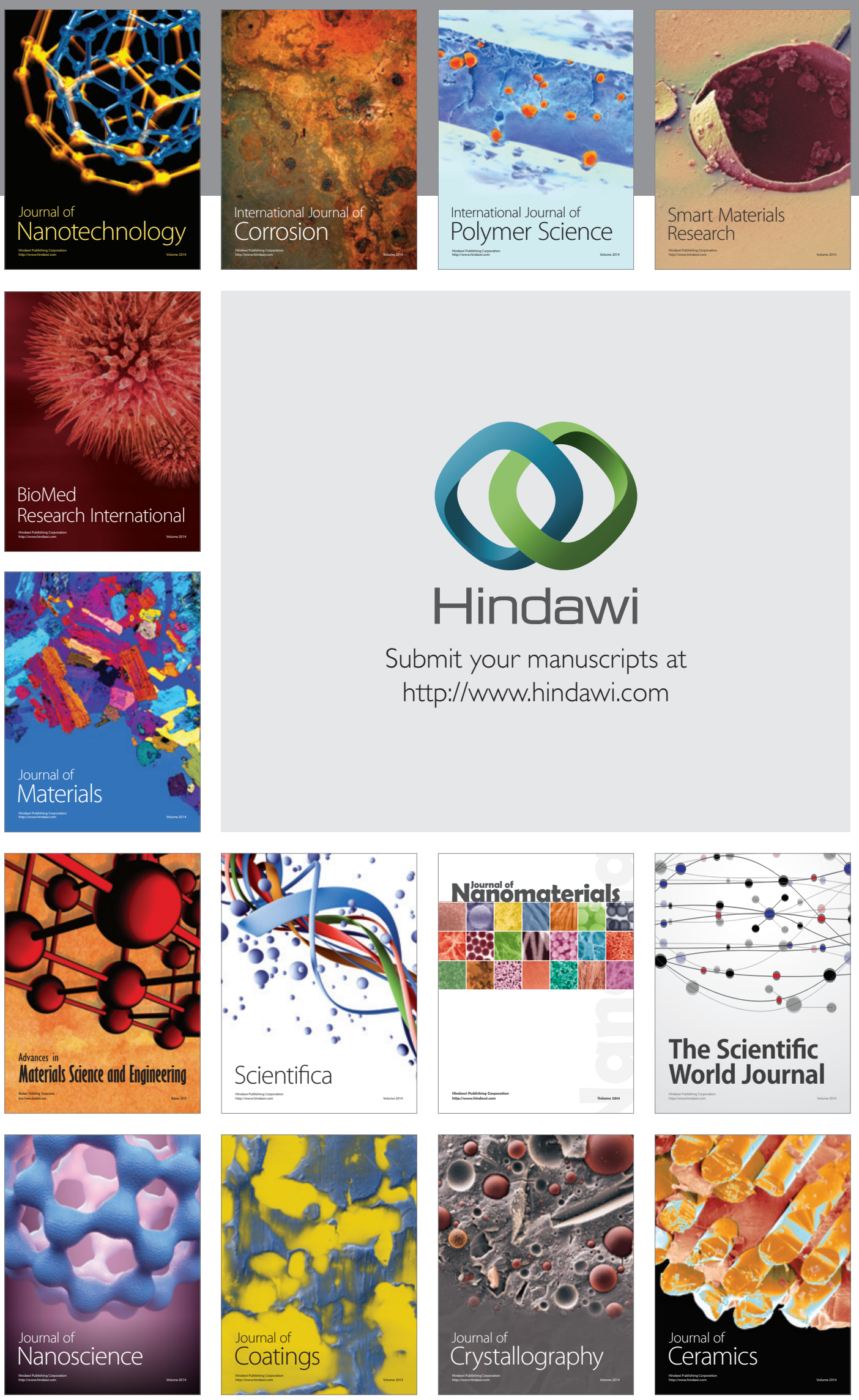

The Scientific World Journal

Submit your manuscripts at

http://www.hindawi.com

\section{World Journal}

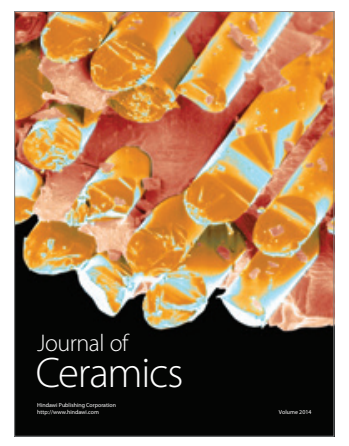

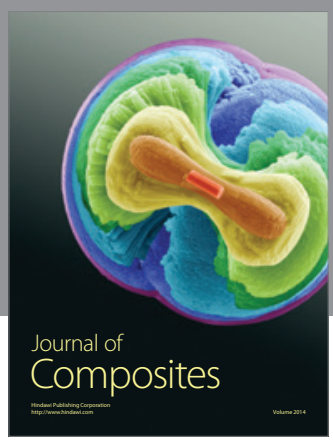
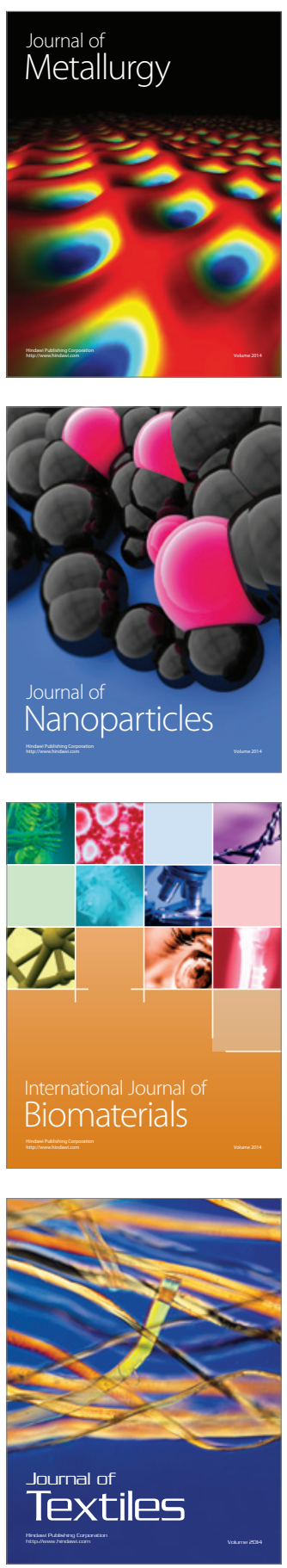